\title{
Optimisation of Ship and Offshore Structures and Effective Waterway Infrastructures to Support the Global Economic Growth of a Country/Region
}

Optimización de Estructuras Navales y Offshore e Infraestructuras fluviales eficaces para apoyar el crecimiento económico global de un país / región

DOI: $10.25043 / 19098642.155$

Philippe Rigo ${ }^{1}$

Abbas Bayatfar ${ }^{2}$

Loïc Buldgen ${ }^{3}$

Timothée Pire ${ }^{4}$

Sara Echeverry ${ }^{5}$

Abstract

Jean-David Caprace ${ }^{6}$

This paper includes the following parts:

- Ship Structure Optimization: methodology to perform ship scantling optimization, decreasing steel weight and keeping the production cost at an acceptable level. We first review the links between "Design" and "Optimization" and secondly define the place of "Ship Structure Optimization" within the general framework of a "Ship Optimization".

- Ship impacts (Collision), with applications to navigation lock and dry dock gates: these gates have to be designed taking into account accidental loads, such as ship collisions. A new simplified analytical method is proposed, based on the so-called super-element method. This method was developed to rapidly assess the crashworthiness of the collided structure and avoid high computational effort of numerical simulations.

- Inland waterway Navigation and the development in South America of Inland Waterway Classifications.

- EMSHIP, European ERASMUS MUNDUS education program (www.emship.eu): the unique master's degree in Ship \& Offshore Structures awarded by the prestigious European Erasmus Mundus Program. EMSHIP shares the outstanding experiences of educators, trainers, industrial partners and students in the rapidly developing areas of marine and offshore engineering industry.

Key words: Navigation, inland waterway, optimisation, ship collision, lock gate, ship structure, analytical method, LBR-5, super-element, EMSHIP, waterway classification

\section{Resumen}

Este documento incluye las siguientes partes:

- Optimización de Estructuras de Barcos: metodología para realizar la optimización del escantillonado de buques, disminuyendo el peso de acero y manteniendo el costo de producción en un nivel aceptable. Primero se revisa los vínculos entre "Diseño" y "Optimización" y en segundo lugar se define el lugar de "Optimización de Estructuras" dentro del marco general de una "Optimización de Buques".

- Impactos de los buques (Colisión), con aplicaciones en puertas de esclusas: estas puertas deben diseñarse teniendo en cuenta cargas accidentales, tales como colisiones de buques. Considerando el enorme esfuerzo computacional de las simulaciones numéricas, se propone un nuevo método analítico simplificado, basado en el denominado método de super-elementos. Este método fue desarrollado para evaluar rápidamente la resistencia a impactos de la estructura colisionada.

- Navegación fluvial y el desarrollo en América del Sur de las Clasificaciones de la Vía Fluvial.

- $\quad$ EMSHIP, programa europeo de educación ERASMUS MUNDUS (www.emship.eu): único programa de maestría en Estructuras Navales y Offshore otorgado por el prestigioso Programa Europeo Erasmus Mundus. EMSHIP comparte las experiencias sobresalientes de los educadores, entrenadores, socios industriales y estudiantes en las áreas de rápido desarrollo de la industria de ingeniería marina y offshore.

Palabras claves: Navegación, navegación interior, optimización, colisión de buques, puerta de esclusa, estructura de buque, método analítico, LBR-5, super-elemento, EMSHIP, clasificación de vías navegables.

Date Received: March 4 ${ }^{\text {th }} 2017$ - Fecha de recepción: Marzo 4 de 2017

Date Accepted: March $13^{\text {th }} 2017$ - Fecha de aceptación: Marzo 13 de 2017

\footnotetext{
${ }^{1}$ University of Liege - ANAST. Belgium. Email: ph.rigo@ulg.ac.be

${ }^{2}$ University of Liege - ANAST. Belgium. Email: A.Bayatfar@ulg.ac.be

${ }^{3}$ University of Liege - ANAST. Belgium. Email: L.Buldgen@ulg.ac.be

${ }^{4}$ University of Liege-ANAST. Belgium. Email: tpire@ulg.ac.be

${ }^{5}$ University of Liege - ANAST. Belgium. Email: echeverry@ulg.ac.be

${ }^{6}$ Universidad Federal de Rio de Janeiro. Brazil. Email: jdcaprace@oceanica.ufrj.br
} 


\section{Introduction}

After presenting of the main research activities at ANAST, ULG, we discuss the way to improve the effectiveness of waterway infrastructures to support the global economic growth of a country/ region.

The paper includes four sections, which cover:

- Ship Structure Optimization;

- Ship impacts (Collision), with application on IW infrastructures including navigation lock gates;

- Inland waterway navigation and the development in South America of Inland Waterway Classifications;

- The European EMSHIP education program in Naval Architecture (www. EMSHIP.EU).

These 4 parts are in fact the pillars of the research and expertise of ANAST, University of Liege; combining naval architecture, ocean engineering, ship and offshore structure with unique expertise in inland waterways as well as in transport system analysis and logistics. All the aspects related to marine and inland waterways aspects are covered, from the ship design and operation, the waterway infrastructure and the transportation economic analysis.

A benchmark international association in which Ph. RIGO disseminates his expertise is PIANC (www.pianc.org). This is the world Association for Waterborne Transport Infrastructure and its forum is where professionals around the world join forces to provide expert advice on cost effective, reliable and sustainable infrastructures to facilitate the growth of waterborne transport. Established in 1885, PIANC continues to be the leading partner for the government and private sectors in the design, development and maintenance of ports, waterways and coastal areas.

PIANC brings together the best international experts on technical, economic and environmental is-sues pertaining to waterborne transport infrastructures. Members include national governments and public authorities, corporations, private companies and interested individuals.
Prof. Ph. Rigo is the chairperson of the PIANC InCom (Inland Navigation Commission) and is the author of several PIANC Reports on Inland Waterway infrastructures (PIANC WG106 - 2009, PIANC WG26 - 2016).

\section{What is new in ship structure optimization?}

\section{Links between "Design" and "Optimization" (Rigo, Caprace, 2011)}

It is impossible to talk about optimization without a clear definition of the design stage(s) which are considered during the design of a ship. If the target is the conceptual design stage, the optimization (tools and objectives) will be completely different from those used for an optimization carried out at the detailed design stage.

"Ship Design" is usually presented through the "Design Loop" or "Design Spiral” (Fig. 1). Each of these design tasks is mandatory to obtain a reliable design of the targeted ship. None of these tasks can be omitted, irrespective of whether the design is for a large cruise vessel, cargo ship, pleasure yacht, tug boat, barge, fishing vessel or navy ship.

These design tasks can be achieved sequentially or simultaneously. In the past, these tasks were performed sequentially but now, for the sake of production efficiency and to reduce the delivery time, most of these tasks are achieved through a concurrent engineering process (Caprace, 2010).

In 2017, performing concurrent design tasks is the current practice. However, today, is it possible to perform concurrent design optimization tasks? Our an-swer to this question is given below.

Ship design optimization is a type of normal task that the naval architect tries to perform during the var-ious loops of the design spiral (whether done sequentially or concurrently). The "Spiral" (Fig. 1) is definitively an optimization process. Each loop can be considered as an iteration of the optimization process. Nevertheless, when the specialists are called in, as is usually the case at 
the contract design stage and even more so at the detailed design stage, the optimization becomes definitively local optimization.

Local optimization is understood as optimization that tackles a single specific issue (hydrodynamics, propulsion, structure, manoeuvrability, etc.), with the other design aspects being suspended. For instance, it is common to consider the hull form and the General Arrangement (GA) as fixed when we optimize the ship structure (scantling) in order to reduce the weight and/or production cost.

Fig. 1. Typical Design Spiral (Eyres 2001)

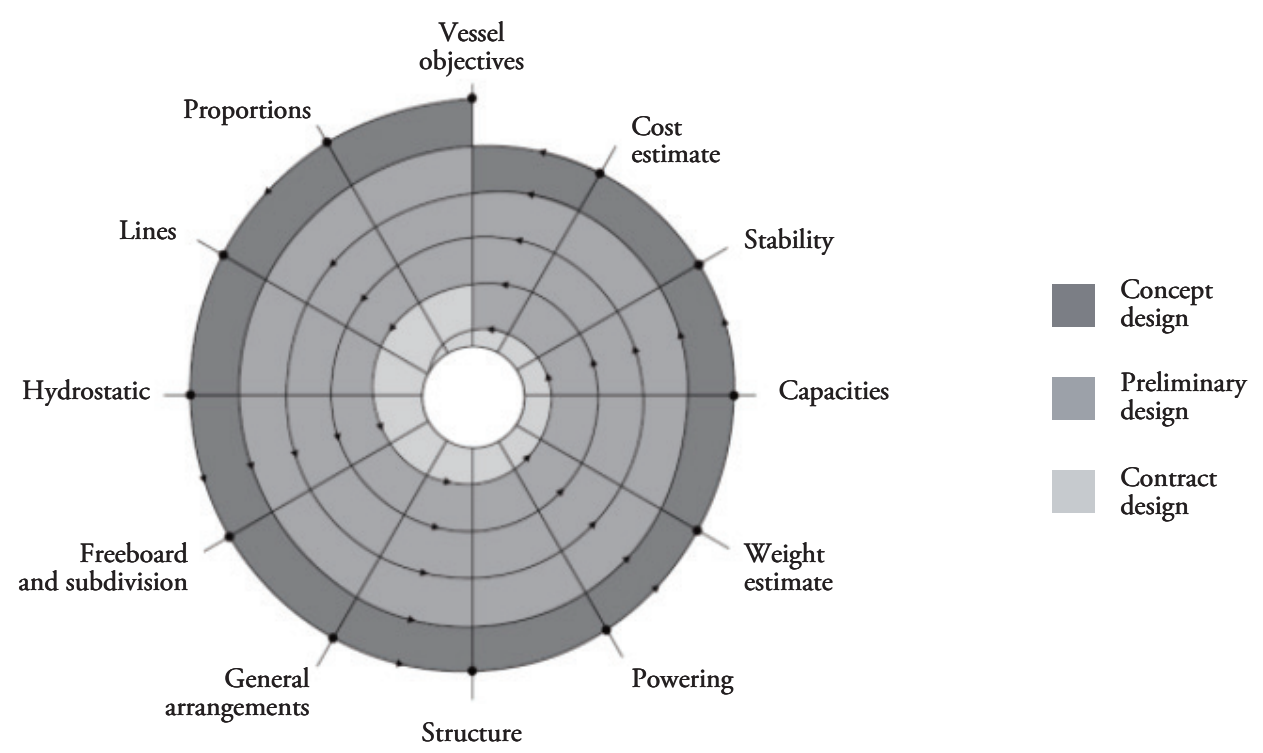

Similarly, in CFD optimization we often consider the structure (scantling, weight, gravity centre, etc.) to be fixed. Alternatively, rules of thumb or statistical curves [weight $=\mathrm{Fct}(\Delta, L, B, T, C b$, etc.)] are used to adjust the weight according to the hull form.

There is also the ship production team which tries to optimize workflow and workload to reduce the delivery time. They are working in the field of Design for Production and the aim is to optimize the ship focusing on the production keeping the other parameters fixed (hull form, scantling, etc.) (Caprace 2008).

It is clear and obvious that it is not efficient to perform sequential local optimization. Nevertheless, even today, it is still the industrial practice used to achieve an improved ship design. Engineers know that they do meet the global optimum but they are moving in the right direction.
Therefore, the solution is definitively to move to a global optimization, by which we mean towards a holistic optimisation (Holiship, 2016). The challenge for tomorrow is therefore to move to a concurrent optimization. That means that several tools will run simultaneously, using the same database and the same design (geometry, loads, hull form, scantlings, etc.).

There were some tentative moves to initiate this procedure [such as VIRTUE (CFD), IMPROVE (RINA 2009) and BESTT (Bayatfar, 2013) for Structure], which are former EU projects. Today, the promising HOLISHIP (2016) EU project has been launched with its target to demonstrate the feasibility of a holistic optimisation using CAESES $^{\odot} \quad$ (Friendship Systems) as the support environment.

All these prior and new projects are facing the same challenges: 
- Difficulty in sharing data. Standard formats are required and must be accepted by the different developers, which are in fact often competitors. Currently, maintaining a different format (standard) is a way to avoid competitors and repulse new developers with alternative modules (which can be more effective than their own module).

- Difficulty in moving from CAD data to CFD, from CAD to structural models (FEM) and above all, from CFD to structural models, and vice versa.

- The level of accuracy of the CAD data is rather different than the expected level required for struc-ture analysis (FEM). Some data may be missing. Nevertheless, more often than not, too much CAD data are available to easily and automatically produce a coarse mesh for FEA. In this case, how can we automatically generate a simplified model from a detailed CAD model, and later, when the optimization is achieved, how can we update a detailed CAD model with data (usually geometric) coming from a coarse mesh FEM? The key issue is to avoid remeshing and manual data transfer, or even worse, retyping the data.

- Most of the tools are in fact "black boxes" for the other developers. Therefore, data exchange is ra-ther slow and cumbersome.

In conclusion, a promising direction of research is the development of a concurrent optimization platform (Holiship, 2016), which could be the intermediate step between a series of sequential local optimization and a full global optimization (which remains a rather long term goal).

In the framework of this targeted holistic and multidisciplinary ship optimization, the next section presents the author views on "multiobjective optimization of ship scantling", the least weight and least cost methods (section 2.2) as well as some outcomes of the BESST project (section 2.3).

\section{LBR-5, a Least Cost Structural Optimization Method}

To be attractive to shipyards, scantling optimization has to be performed at the preliminary design stage.
It is indeed the most relevant period to assess the construction cost, in order to compare fabrication sequences and to find the best frame/stiffener spacings and most suitable scantlings to minimize the life cycle cost of the ship. However at this stage of the project, few parameters (dimensions) have been definitively fixed and standard FEM is often unusable, particularly for design offices and modestsized shipyards. Therefore, an optimization tool at this design stage can provide precious help. This is precisely the purpose of the LBR-5 optimization software, Rigo (2001) and Rigo \& Fleury (2001).

The structural analysis is performed on a model based on an extrusion of the cross section of the structure $(2 \mathrm{D}+)$ solving the stiffened plate differential equations with Fourier series expansions, Rigo (2003).

The LBR-5 structural optimization model is com-posed of several modules and is made up of 3 key modules (objective function, optimization algorithm and structural constraints), which forms the framework of the optimisation tool.

Around the objective function and constraints modules, there are a large number of submodules. Each of these submodules is specific to a type of constraint.

Fig. 2 shows the basic configuration of the LBR5 software with the 3 fundamental modules (objective function, optimization algorithm and constraints).

As an example of application, we present the structural optimization of a cruise ship (Fig. 3). The length (Lpp) is about $280 \mathrm{~m}$.

\section{Load cases}

For each section, the following load cases were considered:

- sagging and hogging wave vertical bending moments with a probability of $10^{-8}$; still water pressures; static deck loads;

- sagging and hogging wave vertical bending moments with a probability of $10^{-5}$; still water and wave pressures; static deck loads; 
Fig. 2. Flow chart of the LBR-5 optimization software (Rigo 2001, and Rigo 2003)

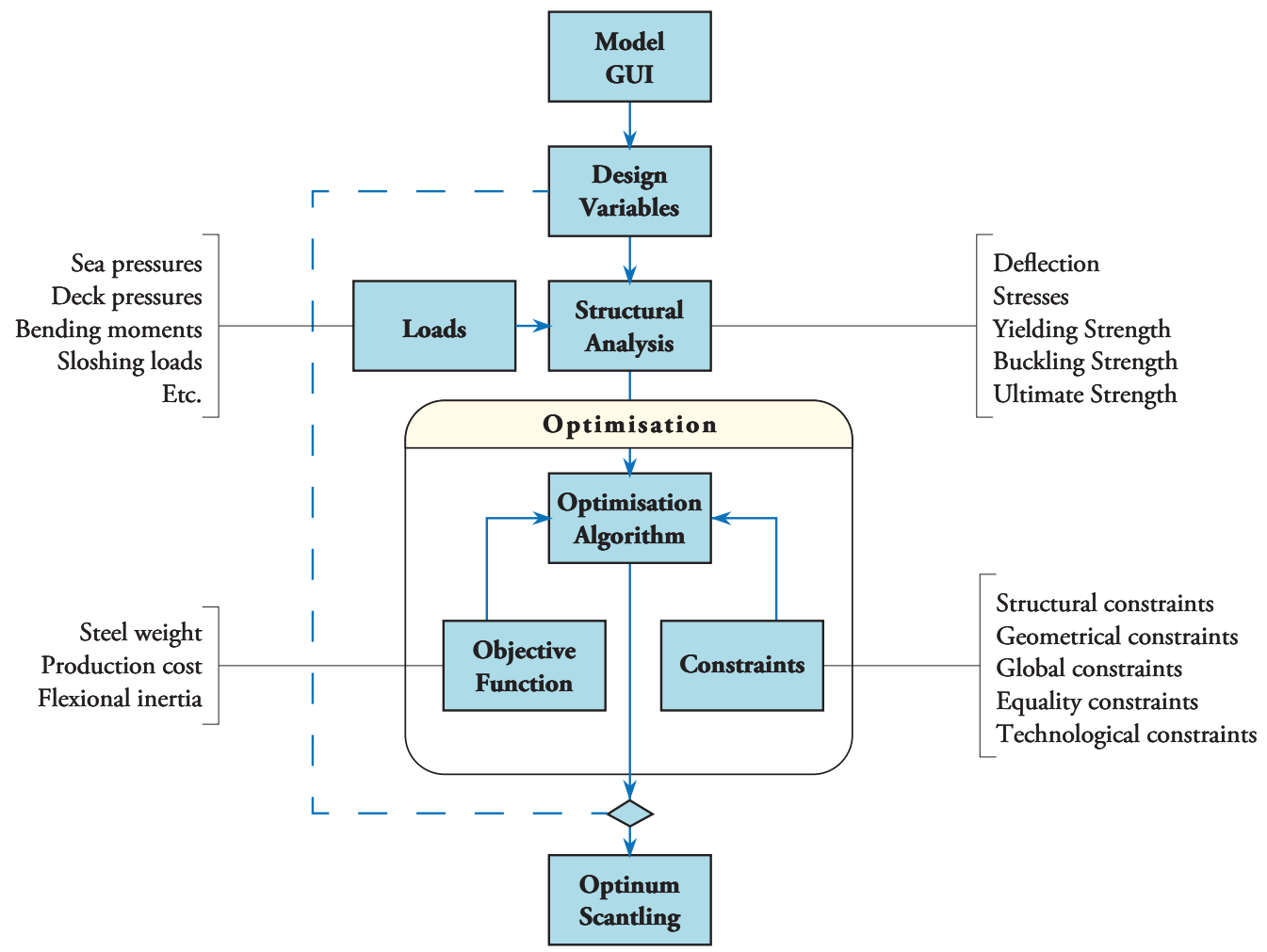

Fig. 3. Three amidships sections of a cruise ship (STX-France)

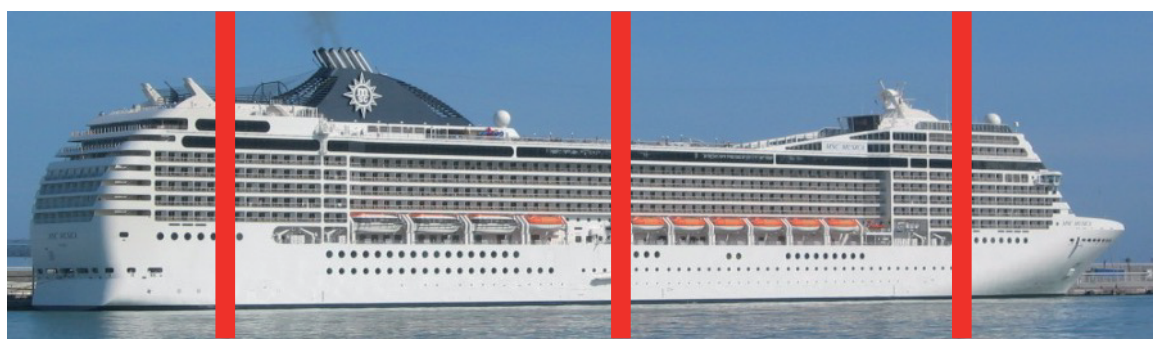

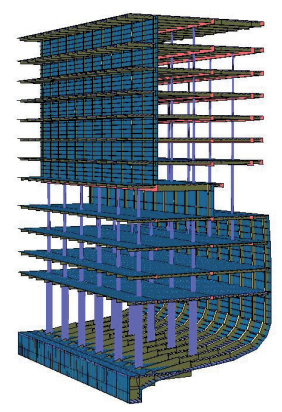

81 panels

24 pillars

Aft ship section [A]

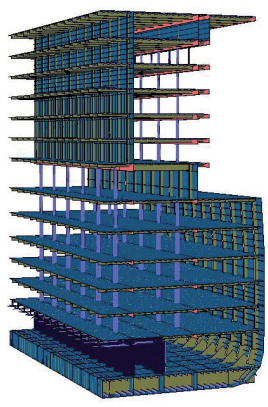

78 panels

25 pillars

Amidships section [M]

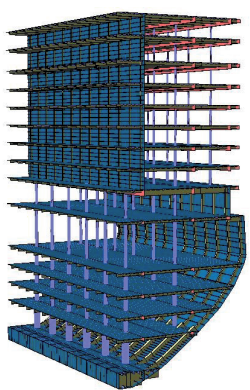

93 panels

28 pillars

Fore ship section [F] 
- maximum still water and wave pressures, without hull bending moment.

\section{Optimization - Design variables}

The three ship sections are modelled with 81,78 and 93 stiffened plate elements respectively. The structural response of the model is solved with the resolution of the nonlinear differential equations of each stiffened plate element, Rigo (2001). For each element, 9 design variables are available:

- Plate thickness.

- For longitudinal members (stiffeners, crossbars, girders, etc.),

- web height and thickness,

- flange width,

- spacing between 2 longitudinal members.

- For transverse members (frames, transverse stiffeners, etc.),

- web height and thickness,

- flange width,

- spacing between 2 transverse members (frames).

In this case, 1694 design variables were activated for the whole ship model (3 ship sections) which represents an average of 6-7 design variables per stiffened panel.

To deal with this huge number of design variables the LBR-5 optimization algorithm solving nonlinear constrained problems has been used. It is based on both a convex linearization of the nonlinear functions and a dual approach, Fleury et al. (1986). It is especially effective because only few FEM reanalyses are required; typically less than 10 .

\section{Optimization - Objective functions}

Production cost and minimum weight constitute the two objectives considered in this application. Production costs (PC) has been subdivided into three categories:

- the cost of raw materials (MC) - The evaluation of material costs consists in quantifying volumes required for construction and obtaining prices from suppliers and subcontractors.

- the labour costs (LC) - This means the labour cost (LC) of a stiffened panel: welding of two as-semblies, the tacking of steel profiles, etc. The production cost has been calculated with an ad-vanced cost module taking into account a detailed shipyard database. Around 60 fabrication operations are considered, covering the different construction stages, such as girders and webframes prefabrication, plate panels assembling, blocks preassembling and assembling, as well as 30 types of welding and their unitary costs, Toderan et al. (2007).

- the overhead costs (OC).

\section{Optimization - Design constraints}

Constraints are linear or nonlinear functions of the design variables which are either explicit or implicit. These constraints are analytical relationships of the limitations that the user wants to impose on the design variables or parameters such as displacement, stress, ultimate strength, etc.

The problem is highly constrained (Table 1) and the adequacy of these constraints can greatly influence the solution provided. In this specific case study,

Fig. 3. Three amidships sections of a cruise ship (STX-France)

\begin{tabular}{|c|c|c|c|c|}
\hline & \\
\hline & $\begin{array}{l}\text { Aft ship } \\
\text { section }\end{array}$ & $\begin{array}{c}\text { Amid } \\
\text { ships section }\end{array}$ & $\begin{array}{l}\text { Fore ship } \\
\text { section }\end{array}$ & Total \\
\hline Number of strake elements & 81 & 78 & 93 & 252 \\
\hline Design variables & 550 & 460 & 684 & 1694 \\
\hline Technological constraints & 1100 & 920 & 1368 & 3388 \\
\hline Geometrical constraints & 558 & 446 & 692 & 1696 \\
\hline Structural constraints & 5734 & 4035 & 7040 & 16809 \\
\hline Global constraints & 2 & 2 & 2 & 6 \\
\hline Equality constraints & 0 & 0 & 0 & 0 \\
\hline Total constraints & 7394 & 5403 & 9792 & 21899 \\
\hline
\end{tabular}


3388 technological constraints, 1696 geometrical constraints, 16809 structural constraints and 6 global constraints have been used.

\section{Pareto front}

For this application case, two objective functions are considered. This results in Eq. 1 where $P$ is the objective function and $F_{1}, F_{2}$ which are both analysed in this paper (the steel weight and the production cost respectively). Furthermore, $F_{1}^{0}$ represents the value of the criterion $F_{1}$ (i.e. steel weight) obtained when the optimization is performed with only this criterion in the objective function (single objective), while $F_{2}^{0}$ represents the value of the criterion $F_{2}$ (i.e. production cost) obtained when the optimization is performed with only this criterion in the objective function (single objective).

$$
P=\left[\left[w_{1}\left|\frac{F_{1}-F_{1}^{0}}{F_{1}^{0}}\right|\right]^{\rho}+\left[w_{2}\left|\frac{F_{2}-F_{2}^{0}}{F_{2}^{0}}\right|\right]^{\rho}\right]^{1 / \rho}
$$

Thanks to the optimization algorithm, all scantlings presented in Fig. 4 are feasible solutions, which mean that all of the constraints imposed on the optimization are being satisfied.

Fig. 4. Pareto front of the cruise ship optimization

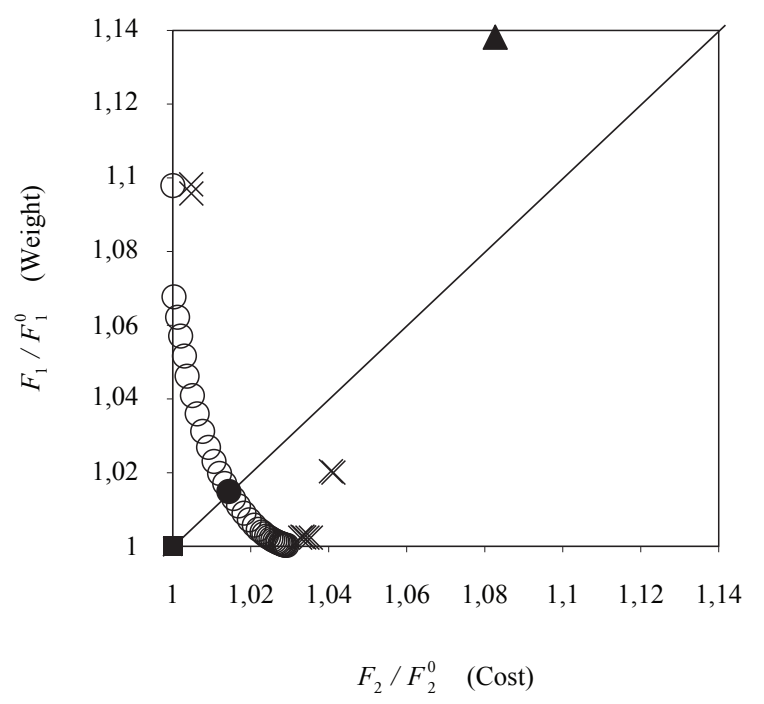

The utopian point, the min-max solution $(\rho=\infty)$, and the initial solution are also shown in Fig. 4. Min-Max solution has been obtained for a weighting factor equal to 0.59 for the production cost and 0.41 for the weight. This analysis has highlighted that the initial design is relatively far from the Pareto front. Using Fig. 4, the design team is now able to choose a compromise solution from the Pareto front, by considering additional factors and constraints that could not be included in the optimization problem.

Table 2. Cost and Steel Weight Savings

\begin{tabular}{|c|c|c|c|}
\hline & $\begin{array}{c}\text { Weight } \\
\text { Optimization }\end{array}$ & $\begin{array}{c}\text { Cost } \\
\text { Optimization }\end{array}$ & $\begin{array}{l}\text { Min-Max } \\
\text { Solution }\end{array}$ \\
\hline & Saving (\%) & Saving (\%) & Saving (\%) \\
\hline $\begin{array}{l}\text { Steel } \\
\text { weight }\end{array}$ & $-12.72 \%$ & $+5.1 \%$ & $-11.3 \%$ \\
\hline $\begin{array}{l}\text { Production } \\
\text { cost }\end{array}$ & $-0.88 \%$ & $-4.52 \%$ & $-1.58 \%$ \\
\hline $\begin{array}{l}\text { Material } \\
\text { cost }\end{array}$ & $-8.5 \%$ & $+0.89 \%$ & $-8.38 \%$ \\
\hline Labour cost & $+4.22 \%$ & $-8.8 \%$ & $+2.96 \%$ \\
\hline
\end{tabular}

\section{Conclusions}

The future challenge in the field of ship structure optimization does not concern the optimization algorithm itself but the development of some specific modules and principally their integration.

The identified challenges and needs are as follows:

- Development of fast and reliable modules to assess structural constraints such as fatigue and loads, at the early design stage (conceptual design stage but more probably at the basic design stage).

- Develop interfaces and/or open platforms for an easy plug and play (integration) of external modules. An initiative started by the IMPROVE user group (RINA, 2009) must be encouraged together with the development of open platforms such as the Holiship (2016) platform.

- Integrate the optimization tools in design chains, with direct links to the major CAD/ CAM tools and FE software to avoid data retyping and time consuming remeshing. 
- Implement multi stakeholders and multi objectives approaches to better converge towards reliable industrial solutions, which are always a fact of comprise between the objectives of the different stakeholders.

- Integrate life cycle cost, and particularly the maintenance and operation costs within the global cost assessment for the entire life of the ship. In that case, optimization will be a supportive design tool toward the "Design for Maintenance" and "Design for operation".

\section{Toward a Ship Structural Optimization} Methodology at the Contract Design Stage

This section presents an innovative workflow toward a ship structure optimisation loop based on the Integrated CAD tool (AVEVA), FEA (ANSYS) and Optimizer (ModeFrontier, 2016). The work was performed in the framework of the research activity carried out by the European Project BESST "Breakthrough in European Ship and Shipbuilding Technologies" (Bayatfar 2013). The focus concerns the development of an optimisation workflow supported by CAD/FEM integration that works automatically without any manual intervention.

In this regard, a typical deck structure was taken into consideration to evaluate the iterative process in the workflow. As shown in Fig. 5, the 3D CAD model is first transferred from the CAD software

Fig. 5. Schematic of optimisation workflow

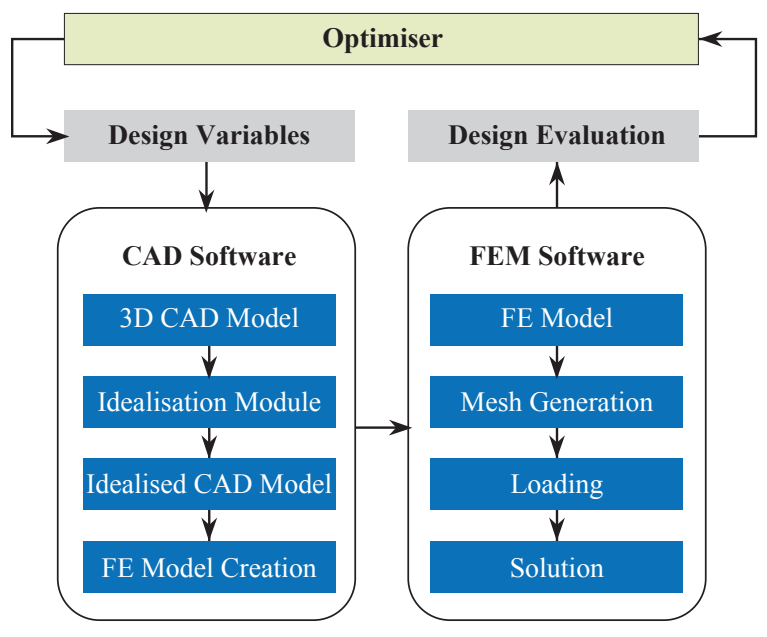

to the idealisation module. Then, the idealisation module generates a simplified geometry which satisfies the FEM needs. After that, the idealised CAD model is transferred to the FEM software to create the meshed and loaded structural model.

Finally, the FE analysis is performed and the results obtained for the objective function and the previously defined con-straints are transferred to the optimiser tool to be evaluated, in order to update the design variables (plate thickness, stiffener dimensions, stiffener spacing, etc.) and to create a new structural model. The optimisation iteration process continues until the convergence is reached.

The deck structure model was created by CAD AVEVA Marine software (2017). The structure is constituted by deck plate, longitudinal girders, transversal frames, longitudinal stiffeners placed between girders, and two longitudinal walls along with its stiffeners. In the AVEVA Marine model, the longitudinal stiffeners placed between girders and the stiffen-ers placed on two longitudinal walls were taken into consideration as beam members (Fig. 6).

\section{Results and discussions}

The AVEVA Marine based optimisation workflow was successfully validated and the obtained results are presented in this section. The communication between all integrated software and tools are a fully automatic process, without any manual intervention on the graphical user interface.

The convergence of the solution is obtained after 246 iterations. The total calculation time for one run is about one minute (the total run takes about 4 hours).

Fig. 8 shows the structural models along with its FE results for various iterations for the AVEVA Marine case study, and shows the convergence histories of the objective function (i.e. the total weight of the structure) and the structural constraint (i.e. the maximum Von Mises stress) with a multihistory chart. The optimum is reached after 209 iterations. 
Fig. 6. Deck structure model - AVEVA Marine

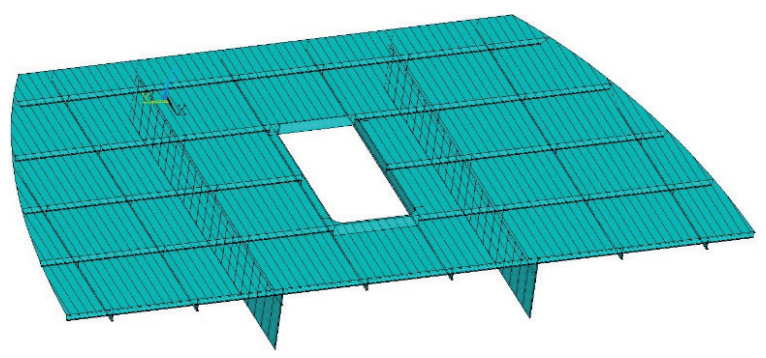

Fig. 7. Typical FE mesh model - Ansys

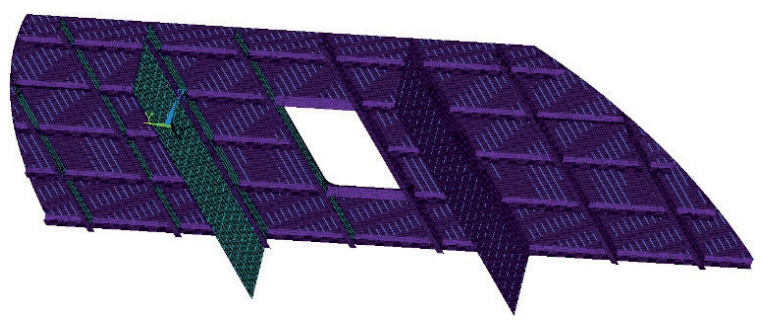

Holiship, an holistic framework for ship optimization (EU project, H2020, 2016-2020)

Holiship (2016): the aim is to develop tools and optimization methodologies for the initial and contract design phase in terms of structure and producibility aspects.

In the detail design phase (Fig 9), CAD and FEM models are available and can be used by Holiship simulation kits to assess and update (optimize) the design considering the owner's and yard requirements.

The Holiship project, in addition to "Hydro" and "Life Cycle", addresses the structural and functional simulation and optimization (Fig. 9). To go into further details there would be development/ workflow for structural simulation/optimization

Fig. 8. Structural models with FE results for different iterations (AVEVA / Ansys)

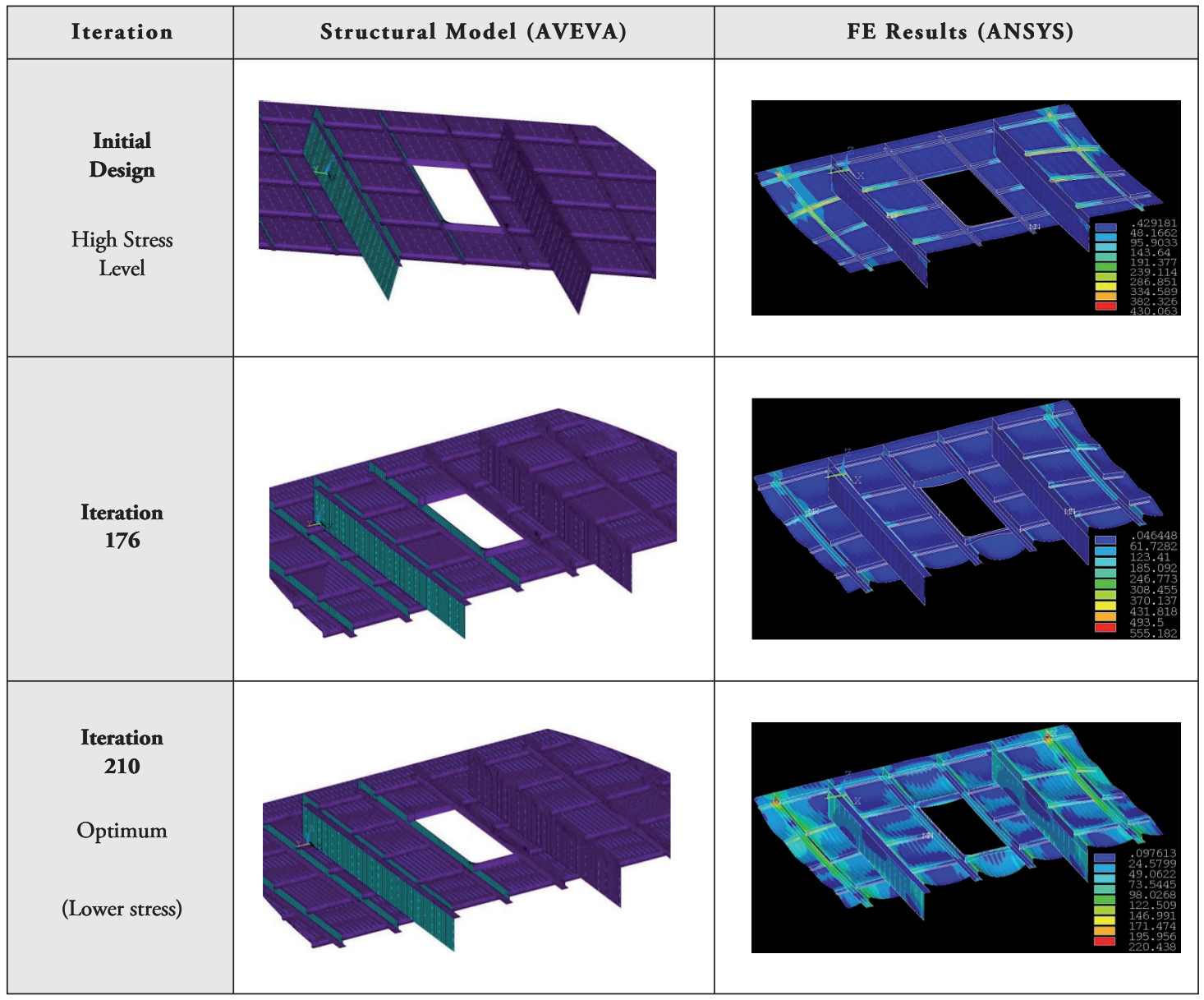


and functional optimization, interacting with each other's in some points.

Here it should be noted that the workflow provided in Fig. 9 is the continuation of the development started in BESST project (FP7).

\section{Acknowledgment}

The authors thank the members of the IMPROVE, BESTT and HOLISHIP European projects. The work was performed in the framework of the research activity carried out by the European

Fig. 9. Structural and functional optimization of the HOLISHIP Integrated Platform (Contract Stage)

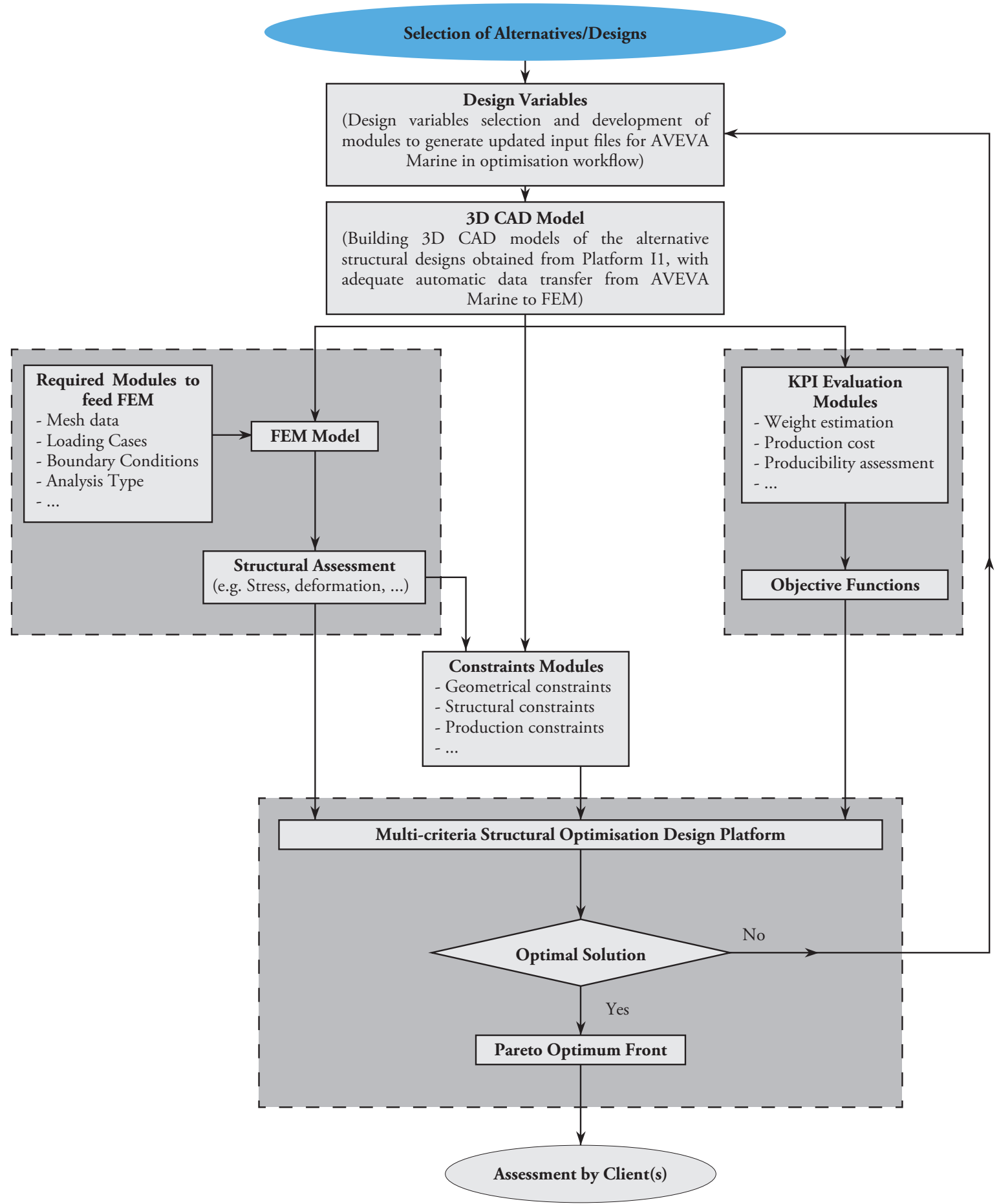


Project BESST. In this regard, the authors wish to acknowledge the support given by European Community's $7^{\text {th }}$ Framework Programme (FP7/2007-2013) under grant agreement $\mathrm{N}^{\circ}$ 233980 which has been led to the results presented in this paper.

Similarly, Holiship project has received funding from the European Research Council (ERC) under the European Union's Horizon 2020 research and innovation programme under Grant Agreement N ${ }^{\circ} 689074$.

\section{Ship impact on inland waterway gate infrastructures}

Worldwide statistical data showed that the freight transport demand has been increasing constantly over years. Currently most of the transit is via roads, but its capacity is reaching the maximum in many parts of the world. Transportation by waterways represents an interesting alternative due to several factors, such as environmental impact (pollution and noise), road congestion, carrying capacity or cost of transport. Transportation by waterways is increasing and is expected to develop further in the near future (PIANC WG139, 2016).

In addition, most international design standards must consider accidental loads when calculating structures such as navigation lock and dry dock gates (PIANC WG106, 2009). This includes, in addition to others, the creation of a ship collision risk analysis, which is the product of the probability of an accident occurring and the related damage (PIANC WG 151, 2014). The occurrence of a ship/ lock gate collision event is low but will increase with the evolution of waterways traffic. However, failure may lead to important consequences on environmental (flood), economic (traffic is stopped, need of repairs, etc.) and social aspects.

Nowadays, design offices mainly use finite element simulations to compute the resistance of a gate impacted by a ship. This method provides accurate results but is time-demanding and therefore is not suitable for the predesign stage and risk based analysis. In any cases, many collisions scenarios have to be investigated as it is difficult to predict the most critical one.

To overcome this issue, simplified analytical methods were developed by the authors to rapidly compute the crushing force of a ship striking a lock gate. The results are validated by comparison with numerical simulations results performed with the finite elements software LSDYNA.

\section{Super-element (SE) method}

The super-element (SE) method (Buldgen, 2014; Le Sourne, 2007) is an analytical method that allows the computing of the behaviour of a structure submitted to a specific loading case, for which the SE was developed.

First, the global structure is decomposed into large structural units, called super-element (SE). Then, analytical formulations are derived to characterise the behaviour of each SE. Finally, an algorithm is developed to combine the effect of all the SE and get the total resistance of the structure.

This methodology was already used for offshore collisions application, in addition to others, by Le Sourne et al. (2012) for ship-ship collisions, by Buldgen, Rigo et al. (2012) for ship/lock gate collisions and by Le Sourne, Rigo et al. (2016) for ship/wind offshore wind turbine (OWT) collisions.

Applications for navigation lock and dry dock gates

Simplified analytical formulations were developed for plane lock gates with a single plating and an orthog-onal stiffening system, suitable for lifting gates, sin-gle leaf gates or horizontally moving gates, but also for mitre gates which is one of the oldest gate types (Buldgen, 2014; PIANC WG139, 2016).

The impact location varies with the ship's direction (upward or downward) and the type of gate (upstream or downstream gate).

When the ship strikes a gate, at the beginning the structure suffers local deformations, as the 
penetration value is low (Fig. 13). The collided area can suffer plastic deformations which might lead to a rupture of some structural elements. As the penetration increases, large out of plane displacements occur to the entire structure and a global deformation appears (Figs. 12, 13).

In order to apply the super-element method, the lock gate must be decomposed into large structural units called "Super-Element (SE)". For a plane lock gate, different types of SE are required, as presented in Fig. 10:

- Type (1) is a plate SE clamped on its four edges which is submitted to out-of-plane displacement. This SE is used to model the plating of the gate which is limited by two horizontal girders and two vertical frames.

- Type (2) is a girder SE used to model parts of frames limited by two girders (vertical elements) or parts of girders limited by two frames (horizontal elements). These SE are considered as plates supported on three edges.

- Type (3) are X or T-shaped SE elements used to model the intersection of the vertical frames with the horizontal girders.

The resistance of the gate $P(\delta)$ can be evaluated by combining the local resistance $P_{1},(\delta)$ and

Fig. 10. The geometry of the gate and the three superelement types considered for modelling

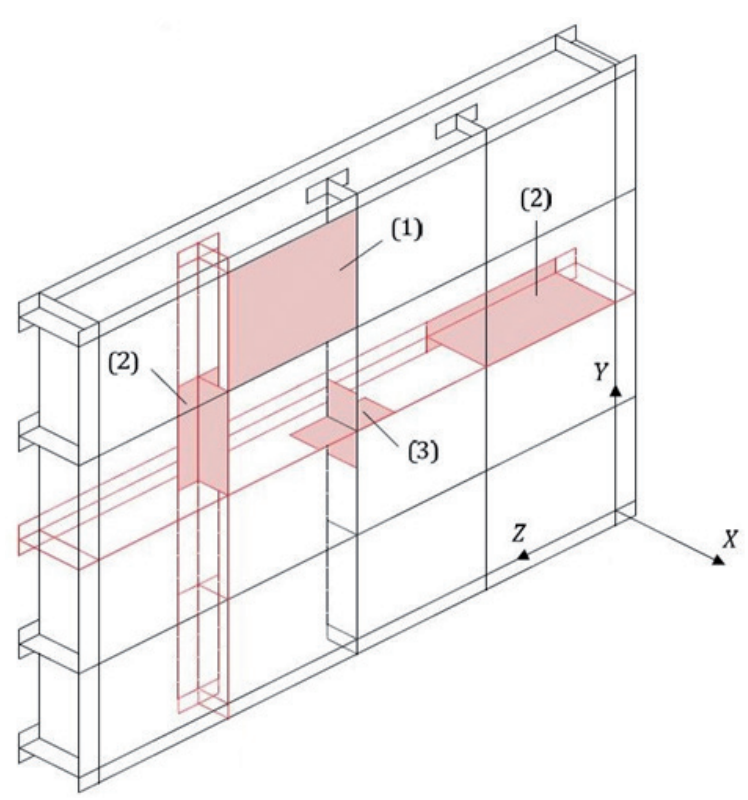

the global resistance $P_{\%}(\delta)$. The local resistance $P_{1}(\delta)$ is defined as the reaction of the gate when only local deformations occur due to ship collision and is only derived for a rigid plastic material, without considering the overall motion of the gate. The global resistance $P_{r}(\delta)$ is defined as the

Fig. 11. Local deformations of a SE Type 3 (Von Mises stresses)

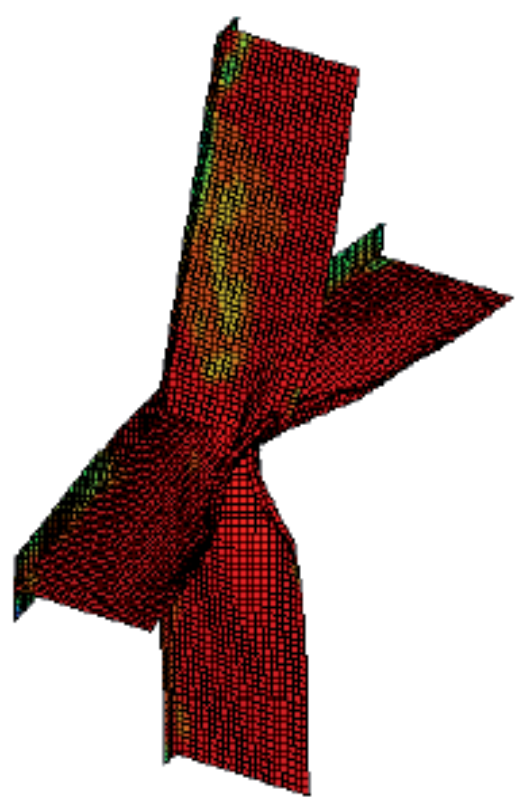

$(\mathrm{MPa})$

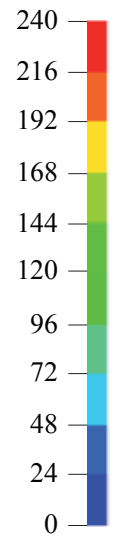

Fig. 12. Global deformation of a plane gate

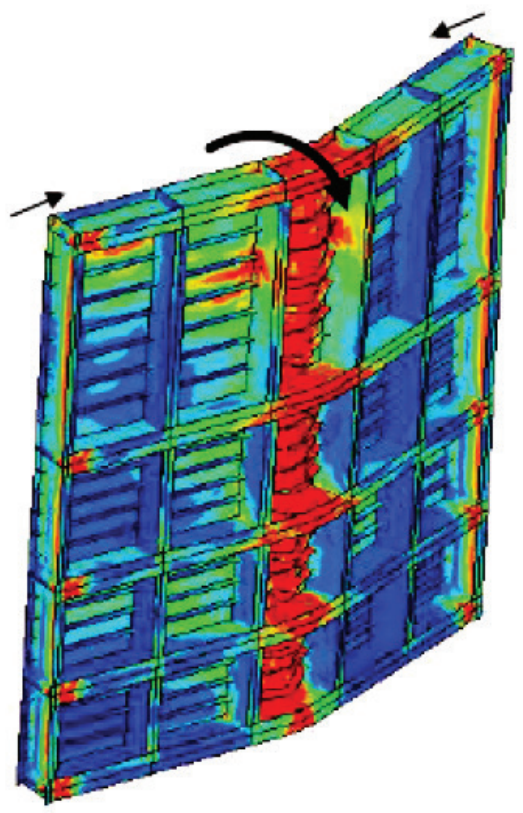


reaction of the lock gate when the striking ship moves forward imposing an overall bending of the structure. First an elastic plastic solution is derived which is combined with the local resistance $P_{1 .}(\delta)$ in order to obtain the resistance during the local deformation mode. Second, the resistance during the global deformation mode is evaluated by using a rigid plastic solution of the global resistance.

The total resistance computed with this analytical method is compared with the results obtained with finite element simulations performed with the LS-DYNA software. The comparison in terms of crushing force and dissipated energy with regard to the vessel penetration for a collision of a typical vessel on a plane lock gate are plotted in Fig. 13.

\section{Development of inland waterway classifications in South America}

South America has to take full advantage of its extensive system of naturally navigable waterways or to integrate them into the region's transport network to cater for the ever-increasing demand for cargo and human mobility. The modal shares of inland shipping in the region's international transport are less than one percent in terms of value and volume (Wilmsmeier and Spengler, 2015). Nevertheless, the evolution of international transport in inland navigation has been positive over the last decade.
Inland waterways are not only used for transport between the countries of the region, located along the river basins, but are also the first leg of international transport flows with other regions of the world. Examples of the latter are natural resource exports (soybean products, aluminium, and oil related products) from the ParaguayParaná, Orinoco and Magdalena river basins that are destined for the Europe, the US or Asia. In these cases, seagoing vessels are directly deployed from the ports along these river systems. While the values of these exports have more than tripled since 2002 , in some waterways the volumes have shown a decreasing tendency over the last years but hopefully not everywhere as in Paraguay-Paraná IW.

In South America, there are several independent inland waterway systems, which have different levels of development. For some of these systems, and from a macro perspective view, the uses of the inland waterway systems in the region are challenged by various factors. These factors include:

- Incomplete, outdated or absent national and regional norms and regulatory frameworks;

- Lack of common inland waterways classifications in South America standardizing the inland navigation at national and 'supranational' levels;

- Lack of standardization of fleets, vessel, and control procedures.

- Lack or absence of investment in the construc-tion and maintenance of waterway infrastructure and inland ports;

Fig. 13. Crushing force and dissipated energy for a ship - plane lock gate collision

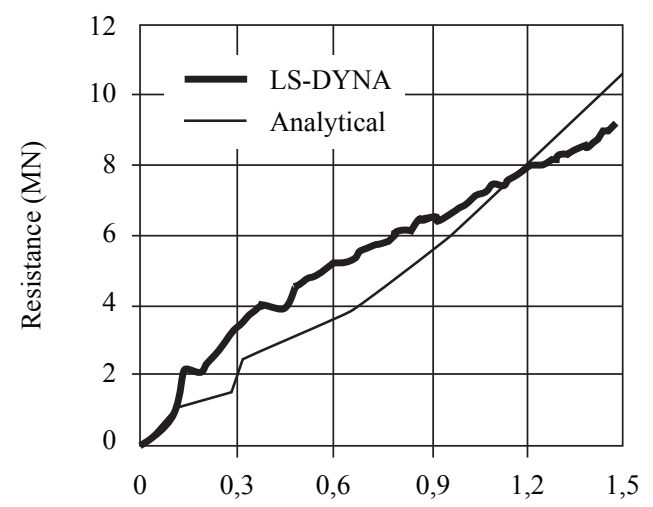

$\delta(\mathrm{m})$

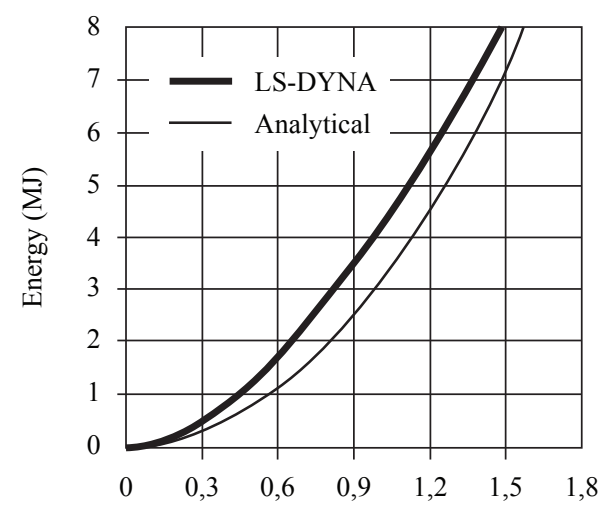

$\delta(\mathrm{m})$ 
- Delay and lack of administrative structures and building of institutional capacity (capacity in this case refers to human and financial capital);

- Lack or absence of navigation aids, including updated maps, electronic charts, signals, and other navigational services as RIS;

- Lack of qualified labour and institutions for capacity building and training of qualified labour

These challenges limit the past, current, and future potential of inland navigation and the current situation affects not only the wider use of this mode of transport, but also its integration with other modes, generates inefficiencies, such as cargo losses, and results in relatively high costs of transport at local, regional, and national level.

A shared inland waterway classification for South America can be a first milestone in developing inland shipping prospects. Indeed, past experiences such as CEMT'92 (1992) have shown that such classifications are far from being a formality or a purely academic exercise, but an essential, powerful and dynamic tool for supporting and implementing inland waterways policies and projects as they allow the limitations and the economic potential of navigable waterways in the region to be identified and to encourage and monitor the development of their capacity for the transport of goods and people (Jaimurzina et al., 2016).

In October 2016, at the ECLAC/PIANC/ ANTAQ Seminar on Inland navigation and a more sustainable use of natural resources: networks, challenges, and opportunities for South America (Rio de Janeiro, Brazil), the representatives of the South American countries (including Colombia) with interest in inland navigation and the PIANC experts (PIANC 1990, 1996, 1999 and 2019 from Europe, Northern America and Asia supported the idea of creating a regional classification for inland waterways in South America and recommended the creation of a dedicated working group on the issue.

\section{Objectives}

The main objective of this initiative (ECLAC, PIANC, 2016) is to develop and implement a strategy for a common supra-national inland waterway classification for South America, combining the knowledge of ECLAC (CEPAL) and PIANC and drawing on the experience of other regions of the world.

\section{EMShip, a unique european master's programme in ship \& offshore structures}

The EMShip programme (www.eship.eu) is unique and it is the only master's degree in "Advance Design in Ship \& Offshore Structures" awarded by the prestigious European Erasmus Mundus Program. Indeed, EMShip shares the outstanding experiences of educa-tors, trainers, industrial partners and students in the rapidly developing areas of marine and offshore engineering industry.

The EMShip Master Course "Integrated Advanced Ship Design - www.EMSHIP.eu” was developed and is run by seven universities in six different European countries (Fig. 14). After 1.5 years (3 semesters) with a total of 90 credits, graduates earn a Dual Degree: one Master Degree awarded by the University of Liege in Belgium: "Advanced Master in Naval Architecture" and the second by the Ecole Central in Nantes, France: "Master of Sciences in Applied Mechanics, specialization in Hydrodynamics, Energetics and Propulsion".

Students enrolled have the opportunity to take lectures in three European countries: after the first semester in Belgium and the second in France, they can decide to either complete their degree at University of Galati in Romania, University of Genoa in Italy, University of Rostock in Germany, West Pomeranian University of Technology in Po-land or at the ICAM (Engineering School) in France (and many others). 
Fig. 14. EMShip Partners - www.EMShip.eu

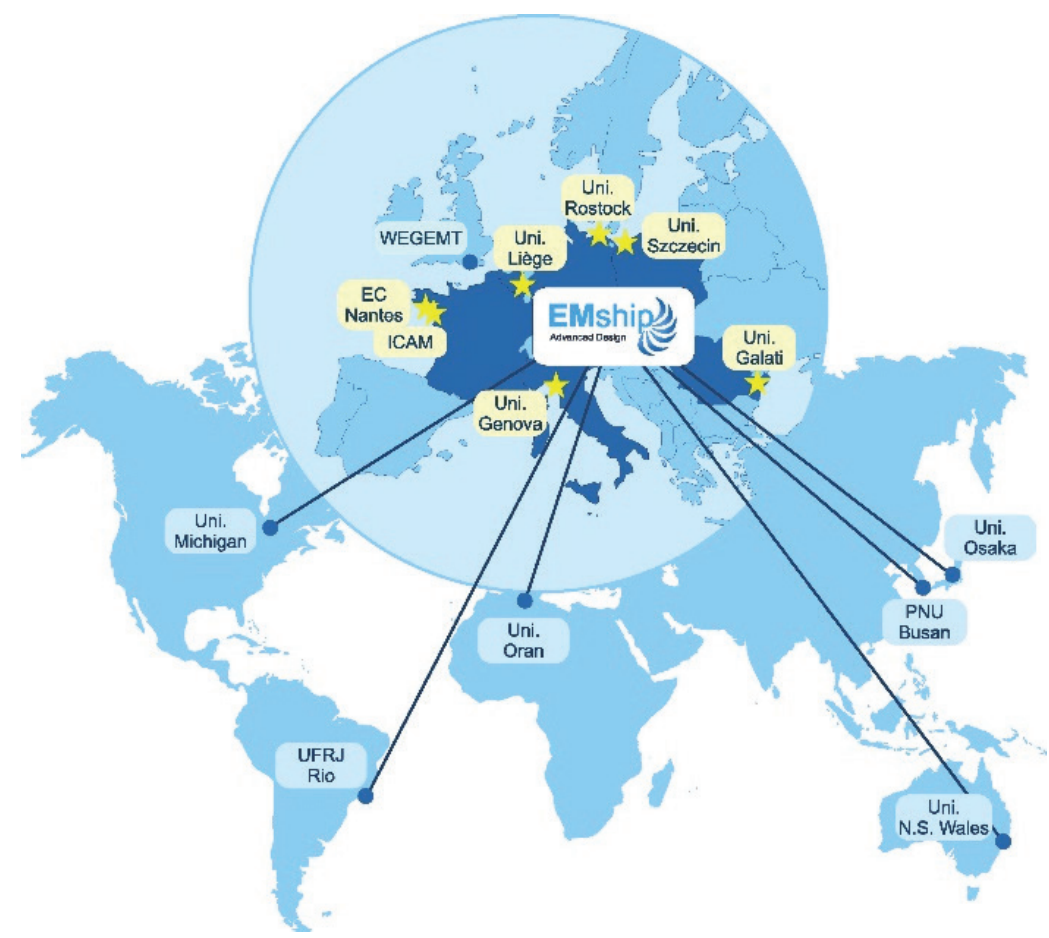

\section{Mobility Scheme}

The mobility scheme, being a fundamental component of the programme, gives the students the opportunity to experience a variety of academic and cultural environments and to greatly benefit from the multicultural nature of the student population in the master's degree course and the networking instruments for students and staff. An internship forms an integral part of the programme for which many leading European maritime companies offer positions as they strongly support the international EMShip EMMC. In reality this setup means that students have to take residence at four locations in Europe (and sometimes worldwide) while being enrolled in the EMShip programme.

\section{Industry Relevance}

Shipbuilding is a fundamentally interdisciplinary discipline which has always been global and provides the means for an economically and ecologically highly efficient and safe transport. Europe has developed a clear perspective on maritime technologies as waterborne transport is regarded as being essential for economic and ecologically sustainable growth. The European maritime industry holds a firm market position; the need fot competent partners worldwide with a sound knowledge of European culture and values, with valuable experiences achieved in Europe is regarded as being inevitable.

Europe for example holds the leading position in developing and supplying ship design consultancy, complex ship onboard systems, passenger vessel and mega yacht design and production with many famous shipyards in Italy, France, Germany, Holland and Finland. A similar situation is observed in the offshore market. This business has been booming for several years in Norway and the UK (oil and gas), Denmark and Germany (wind energy turbines). Innovative, modern ships (PSV, OSV) and offshore installations are designed, repaired and produced in Norway and Poland.

\section{Global Network}

To be able to recruit the best students, to be aware about the demands of the students from all over 
the world and to continuously develop the quality of the program, 8 additional associated partner universities have joined the consortium (Fig. 14). These are the University of Michigan (NA\&ME, USA), University of Osaka (NAOE, Japan), Federal University of Rio de Janeiro (UFRJ, Brazil), University of New South Wales (UNSW, Australia) and the Pusan National University (NPU, Korea).....

\section{Recruitment Statistics}

In February 2017, after 7 intakes, more than 170 students will have graduated from the EMSHIP program, including 6 Colombians (two from COTECMAR). These students have been selected from almost 2000 applicants strictly following a selection scheme, mainly based on the students' skills and results achieved in their previous Education program (MSc, MSc). Additionally the consortium selects students in such a way that each yearly cohort is an international group with a large diversity of ori-gins and backgrounds, guaranteeing a study environment which fully supports a qualification on an inter-national level (Fig.15).

\section{Acknowledgments}

The EMSHIP Consortium Universities warmly thank the Erasmus+ Programme of the European Union for their support.

\section{Conclusion \& promotion of an effective waterway infrastructures to support the global economic growth in South America}

Rivers and waterways are natural transportation modes and we should use them more extensively to sustain the future world economic development, and particularly in South America.

The economic development of a country or a re-gion always requires effective transportation modes. Our purpose is not to promote Inland Waterways (IW) versus road or train, but to claim that a sustainable future development requires the sustainable transportation of goods and persons. This can only occur by using multi modal transportation, combining sea transport, Inland navigation, road, train (and air).

Fig. 15. Nationalities of EMSHIP students

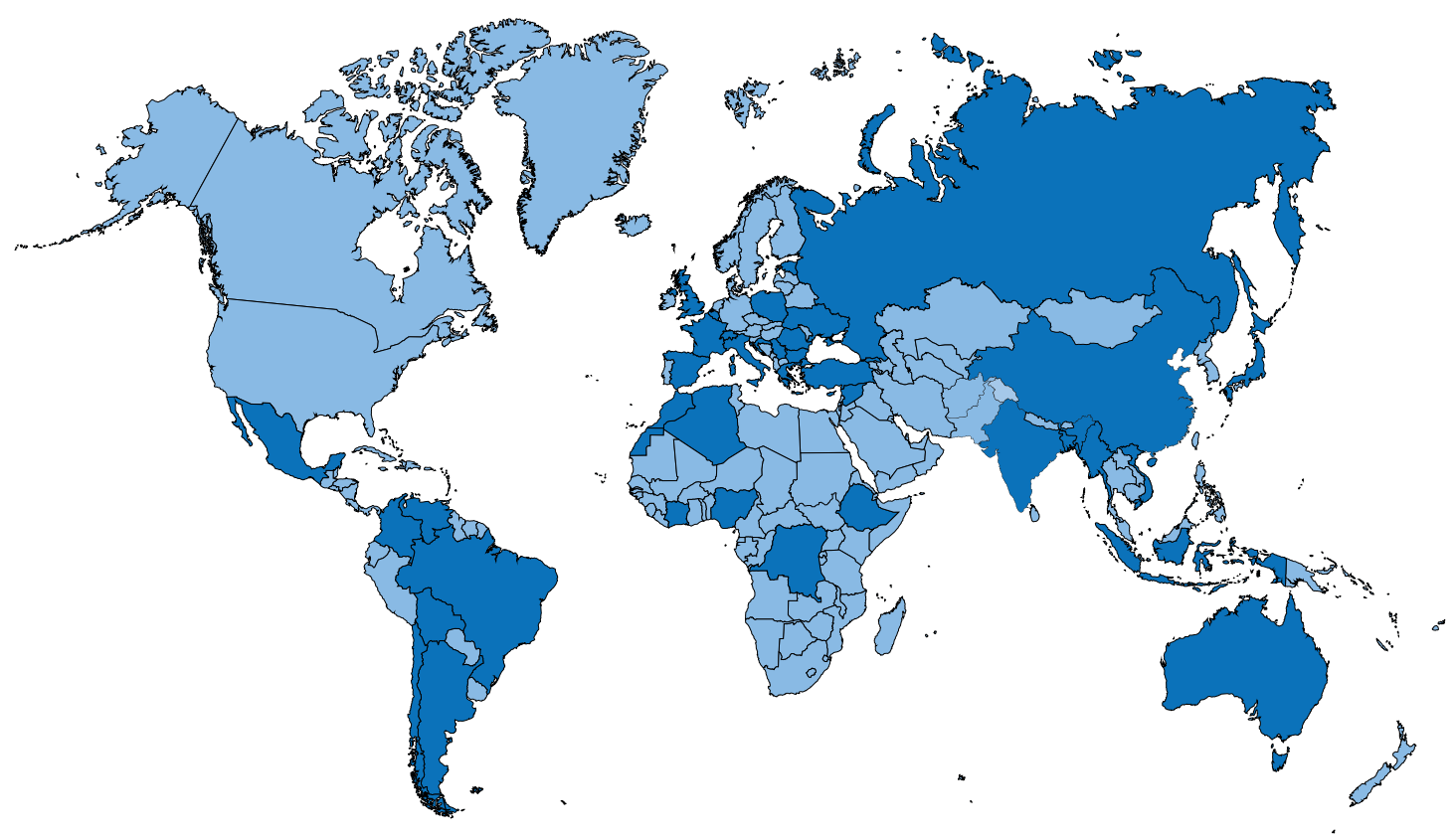


To reach said sustainable development, the share of the inland navigation must be increased, as it is much more environmental friendly than other modes.

Inland navigation and their associated waterways infrastructure elements (port, quay, navigation, lock, flow regulation weirs, dredging, etc.) are not only important for transportation but also for:

- Hydro-electricity $\rightarrow$ power plant;

- Environment protection (fishes, plants, etc.) $\rightarrow$ fish passages and natural bank protection;

- Tourism (along the rivers, and on the river, yachting), walk paths along rivers and parks, ports and marinas, etc.;

- Fishing activities (quay, port, etc.);

- and of course, flood protection (dredging, flood-ing areas, etc.).

In the modern cities, all these activities related to waterways must be considered, none can be neglected, otherwise the "public, the media, and lobbies" will not accept it.

Therefore, our recommendation is to develop a strategic plan to develop natural waterways and move to a "waterway of the future", which will be multidisciplinary tools to promote the economic but also social, living and sustainable environment. The proposal of CEPAL and PIANC to establish specific waterway classifications in South America could be the first step.

In parallel to that, specific studies on waterway in-frastructures must be performed (for more information see www.PIANC.org) and also on the design of specific inland waterway ships/vessels (cargo, LNG, passengers, etc.) and the associated facilities (ports and multimodal platforms), for inland navigation, in universities, research centres, public administrations, and various associations such as COTECMAR.

Inland navigation requires multidisciplinary knowledges and expertise [technical (for ship and infrastructures), economic (transport model), social and environmental]. Ship designers and ship owners cannot improve the navigation (and economic growth) by themselves, they should collaborate with waterway managers responsible for infrastructures and with the persons/companies/ associations who are living, using and working along/on the waterways.

\section{References}

ANSYS (2013), User's Manual, Houston, Swanson Analysis Systems Inc.

AVEVA (2017), Aveva Marine, www.aveva.com.

BAYATFAR A., AMRANE A., RIGO Ph. (2013), Towards a Ship Structural Optimisation Methodology at Early Design Stage, Int. J.of Engineering Research and De-velopment, www.ijerd.com, Vol. 9, Issue 6 , pp.76-90.

BULDGEN, L., LE SOURNE, H., RIGO, P. (2012) A simplified analytical method for estimating the resistance of lock gates to ship impacts, Journal of Applied Mathematics, p. 1-39.

BULDGEN, L. (2014) Simplified analytical methods for the crashworthiness and the seismic design of lock gates. PhD Thesis, Belgium, University of Liège.

CEMT'92 (1992) Resolution 92/2 on new classification of inland waterways, European Regulation's, Brussels.

CAPRACE, J.D. 2010, Cost Effectiveness and Complexity Assessment in Ship Design within Concurrent Engineering and Design for X framework. PhD thesis. University of Liège.

CAPRACE, J.D.; Bair, F.; Losseau, N.; Warnotte, R.; Rigo, P. 2008. OptiView - A Powerful and Flexible Decision Tool Optimising Space Allocation in Shipyard Workshops. COMPIT'08, pp. 48-59. 
ECLAC, PIANC (2016), Position Paper, Inland waterways classification for South America: core concepts and initial proposals, December.

EYRES, D.J. 2001. Ship Construction. Butterworth and Heinemann.

Fleury, C.; Braibant, V. 1986. Structural Optimization: a New Dual Method using Mixed Variables, Int J Numer Methods Eng., No. 23, Vol. 409, p.28.

HOLISHIP 2016, HOLIstic optimisation of SHIP design and operation for life cycle, H2020 EUProject 2016-2020, Grant n689074-2. www.holiship.eu

JAIMURZINA, A. and WILMSMEIER, G. (2016), "Inland navigation and a more sustainable use of natural resources: networks, challenges, and opportunities for South America", November, Bulletin FAL 351, ECLAC.

LE SOURNE H. et al. (2007), A ship collision analysis program based on super-elements method coupled with large rotational ship movement analysis tool, Proceedings of the 4th Int. Conf. on Collision and Grounding of Ships, Hamburg, Germany.

LE SOURNE, H., PIRE, T., HSIEH J.R., RIGO, P. (2016) New analytical developments to study local and global deformations of an offshore wind turbine jacket impacted by a ship. Proceedings of Int. Conf. on Collision and Grounding of Ships, Korea, Pusan.

ModeFRONTIER (2016), Software for Innovative optimization environment with modular, profiled-based access, www.esteco.com/ modefrontier

PIANC WG106 (2009), Innovations in Navigation Lock Design, PIANC report, Brussels,

PIANC WG139 (2016), Values of Inland Waterways, PIANC report, Brussels,
PIANC WG 151 (2014), Design of Lock Gates for Ship Collision, PIANC report, Brussels,

PIANC WG26 INCOM. (2006). Design of movables Weirs and Storm Surge Barriers, PIANC, Brussels, Belgium. http://hdl.handle. net/2268/28139

PIANC (1990), "Standardization of Inland Waterways", Dimensions: Report of the WG9 PTC I., PIANC, Brussels.

PIANC (1996), "Standardization of Ships and Inland Waterways for Rivers/Sea Navigation", Report of WG16, PTC1., PIANC, Brussels,

PIANC (1999), "Factors Involved in Standardizing the Dimensions of $\mathrm{Vb}$ Waterways (canals)", Report of WG20, PTC1., PIANC, Brussels.

PIANC (2009), Working Document 'Calibrating the navigable waterways of the Mekong river system into a classification standard'.

RIGO, P. 2001. Least Cost Structural Optimization Oriented Preliminary Design, Journal Ship Production vol 17., SNAME, USA.

RIGO, P. 2001. A Module-Oriented Tool for Optimum De-sign of Stiffened StructuresPart I, Marine Structures No. 14, Elsevier, pp.611-629.

RIGO, P; FLEURY, C. 2001. Scantling optimization based on convex linearizations and a dual approach-Part II, Marine structure, Elsevier, Vol. 6, pp.31-49.

RIGO, P. 2003. An Integrated Software for Scantling Optimization and Least Production Cost, Ship Technology Research, SchiffahrtsVerslag "Hansa", vol.50, 2003, pp.126-141.

RIGO, P.; CAPRACE, JD. (2011). Optimisation of ship struc-tures. In Marine Technology and Engineering, Guedes Soares (Eds.), London, United Kingdom: Taylor \& Francis Ltd., pp. 925-944. http://hdl.handle.net/2268/126690 
RIGO P.; BRONSART R.; TACZALA M. (2015), EMSHIP+, A Unique European Master Programme in Ship \& Offshore Structures, RINA conf. on Education \& Professional Development of Engineers in the Maritime Industry, 9-10 December 2015, London, UK.

RINA 2009, Move to IMPROVE LNG Carrier Design, The Naval Architect, May 2009.

TODERAN, C.; PIRCALABU, E.; CAPRACE, J.; RIGO, P. (2007) Integration of a BottomUp Production Cost Model in LBR-5 Optimization Tool, COMPIT 2007, pp.225233.
WILMSMEIER, GORDON y THOMAS SPENGLER (2015), «La evolución de la distribución modal del transporte de mercancías en América del Sur entre 2000 y 2013», No. 343, Santiago, CEPAL.

ERASMUS MUNDUS+ Programme,

http://eacea.ec.europa.eu/erasmus_mundus/ results_compen-dia/selected_projects_ action_1_master_courses_en.php

EMSHIP and EMSHIP+; www.emship.eu, coordinated by ULg, Dr. Rigo Ph, ph.rigo@ ulg.ac.be 